\title{
Effects of applying preslaughter feed withdrawal at the abattoir on behaviour, blood parameters and meat quality in pigs
}

\author{
F.A. Dalla Costa ${ }^{\mathrm{a}, \mathrm{b}}$, N. Devillers ${ }^{\mathrm{c}}$, M.J.R. Paranhos da Costa ${ }^{\mathrm{a}, \mathrm{b}}$, L. Faucitano ${ }^{\text {c,* }}$ \\ a Programa de Pós-Graduação em Zootecnia, Faculdade de Ciências Agrárias e Veterinárias, Universidade Estadual Paulista, Jaboticabal, SP, Brazil \\ b Departamento de Zootecnia, Faculdade de Ciências Agrárias e Veterinárias, Universidade Estadual Paulista, 14884-900 Jaboticabal, SP, Brazil \\ c Agriculture and Agri-Food Canada, 2000 College Street, J1M 0C8 Sherbrooke, Quebec, Canada
}

\section{A R T I C L E I N F O}

Article history:

Received 29 September 2015

Received in revised form 21 March 2016

Accepted 24 March 2016

Available online 9 April 2016

\section{Keywords:}

Behaviour

Fasting

Lairage time

Meat quality

Pigs

Stress

\begin{abstract}
A B S T R A C T
To study the effects of starting time of feed withdrawal on behaviour during loading and lairage, and meat quality $(\mathrm{pH}$, colour and drip loss) in pigs, a total of 700 pigs were distributed into two groups. One group (FARM) was fasted for $18 \mathrm{~h}$ at the farm before transport and for $6 \mathrm{~h}$ before slaughter (including $2 \mathrm{~h}$ transport and $4 \mathrm{~h}$ lairage), while for the other group (PLANT) fasting time started at the departure from the farm $(2 \mathrm{~h}$ transport plus $22 \mathrm{~h}$ lairage). Total fasting time was $24 \mathrm{~h}$ before slaughter for both groups. Fasting treatments did not influence blood parameters. PLANT pigs had longer fights $(P<0.05)$ than FARM pigs during lairage and produced darker $(P=0.02)$ and drier $(P=0.03)$ loins. Based on the results of this study, it may be preferable to commence feed withdrawal at the farm.
\end{abstract}

Crown Copyright @ 2016 Published by Elsevier Ltd. All rights reserved.

\section{Introduction}

Feed withdrawal is a recommended practice for on-farm preparation of pigs before slaughter in order to prevent animal losses or travel sickness during transport (Averós, Knowles, Brown, Warriss, \& Gonsálvez, 2008; Bradshaw et al., 1996; National Farm Animal Care Council, 2014), to reduce carcass contamination due to lower risk of gut contents spillage during carcass evisceration (Saucier et al., 2007) and to improve pork quality (Faucitano, Chevillon, \& Ellis, 2010). A feed withdrawal time between 16 and $24 \mathrm{~h}$ appears to be an acceptable compromise to obtain optimal carcass yield and pork quality and safety (Eikelenboom, Hoving-Bolink, \& Sybesma, 1991; Faucitano et al., 2010). The application of this on-farm fasting interval has been also reported to decrease the proportion of dead-on-arrival (DOA; Guàrdia, Gispert, \& Diestre, 1996) and total transport losses (DOA and non-ambulatory pigs; Stewart, Ritter, Culbertson, Mann, \& Wofford, 2008).

Despite these potential advantages, however, fasting is sometimes only applied from the departure from the farm to the abattoir in Canadian swine farms (Aalhus et al., 1992; Viau \& Champagne, 1998). The reason for this misapplication is the producers' concern about the risk of slower growth rate of pigs remaining in the pen and the lack of a shipping room where the heaviest pigs can be transferred to ahead of loading time and feed be withdrawn at the same time (Viau \&

\footnotetext{
* Corresponding author.

E-mail address: luigi.faucitano@agr.gc.ca (L. Faucitano).
}

Champagne, 1998). If, on one hand, this practice may still prevent the risk of full stomachs at slaughter, provided the 16-24 h fasting time is respected by imposing longer lairage time at the abattoir, on the other hand, it may reduce the welfare of pigs during transport and handling (Guàrdia et al., 1996; Stewart et al., 2008). Furthermore, longer lairage time is known to result in higher risk of fighting in mixed groups of pigs leading to higher incidence of dark, firm and dry (DFD) pork (Faucitano et al., 2010; Guàrdia et al., 2005, 2009).

The objectives of this study were to study the effects of starting time of fasting preslaughter, either on-farm or at the departure from the farm, on behaviour during loading and lairage, blood parameters and carcass and meat quality in pigs.

\section{Material and methods}

All experimental procedures performed in this study were approved by the institutional animal care committee on the basis of the current guidelines of the Canadian Council on Animal Care (2009).

\subsection{Animals and treatments}

In this study, a total of 700 crossbred pigs raised at a commercial swine growing-finishing farm and fed a standard commercial diet were randomly selected, tagged, weighed and distributed into two groups of 350 pigs each (BW: $123.7 \pm 4.0 \mathrm{~kg}$ and $123.2 \pm 3.9 \mathrm{~kg} ; P=$ 0.25 ) on the day before the departure from the farm to the abattoir. 
The first group (FARM) had feed withdrawn for $18 \mathrm{~h}$ at the farm before the transport (feeder locked at $1 \mathrm{pm}$ ), loaded at $7 \mathrm{am}$, transported for $2 \mathrm{~h}$ and kept in lairage at the abattoir for $4 \mathrm{~h}$ before slaughter, whereas the second group (PLANT) had access to the feeder until start of loading ( $1 \mathrm{pm})$, was transported for $2 \mathrm{~h}$ and kept in lairage at the abattoir for $22 \mathrm{~h}$. Overall, a $24 \mathrm{~h}$ feed withdrawal time prior to slaughter was applied for both groups. At the time of loading for each transport ( 7 trips in terms of one per week) one batch of 50 pigs per fasting treatment was formed by collecting pigs randomly (or mixed) from 11 pens within each treatment based on the slaughter weight. Pigs were thus shipped to the abattoir over 7 slaughter days (weeks or replicates; 50 pigs $\times 2$ treatments $\times 7$ replicates). Pigs were loaded onto two similar trucks (one truck/treatment) in groups of 5 pigs by a trained handler using paddles and boards and transported at a loading density of $0.43 \mathrm{~m}^{2} /$ pig. The handler at the farm, and the two drivers and trucks were the same throughout the 7 weeks. A randomization of truck loading order and drivers was done at each load to avoid the confounding effect of the truck and driver on the response of the pigs to transport, as reported in previous studies (Peeters et al., 2008; Schwartzkopf-Genswein et al., 2012).

On arrival at the abattoir, pigs were unloaded using a whip only and driven to separate lairage pens on the basis of the treatment group as they were in the truck (25 pigs; no mixing). In each lairage pen, pigs were kept at a stocking density of $0.58 \mathrm{~m}^{2} / \mathrm{pig}$. At the end of the lairage period, pigs were driven to a $\mathrm{CO}_{2}$ stunner and exsanguinated in the prone position.

\subsection{Behavioural observations}

\subsubsection{Behaviour at loading}

Behaviour of pigs during loading was recorded using three digital camcorders (DCR-HC48; Sony, Sony of Canada Ltd., Toronto, Canada), two installed in the alley to the loading ramp and one in the loading ramp. All occurrences of pig behaviours and handler interventions (Table 1) were counted for each loading group of 5 pigs from a predetermined start gate in the farm alley up to the trailer gate for an overall distance of $12 \mathrm{~m}$. Video recordings were analyzed by two trained observers using a handheld Psion Workabout computer (HC-110, Psion Inc., Mississauga, Canada). Inter-observer agreement was $91.8 \%$. The total time taken to load the treatment pigs from the starting gate to the trailer gate averaged $25.6 \pm 3$ min.

\subsubsection{Behaviour during lairage}

Behaviour during lairage was recorded using video cameras (WV-BP50, Panasonic Canada Inc., Mississauga, Canada) installed over the pens and connected to a digital encoder (Nextiva S5712e, Verint, Melville, NY). Images were captured by the Omnicast system (version 4.0; Genetec Inc., Montreal, Canada) at a frequency of 5 to 7 images/s during two periods of lairage which excluded the time of showering (first $20 \mathrm{~min}$ and last $40 \mathrm{~min}$ of lairage time) to avoid the confounding effect of this practice on pig behaviour (Weeding, Guise, \& Penny, 1993). The first period was of 2 and $3 \mathrm{~h}$ for FARM and PLANT pigs, respectively, and started from the end of the first shower, while the second period covered the last $2 \mathrm{~h}$ of lairage before the start of the last shower. Scan sampling was used at 2 min intervals to determine the number of pigs lying down. Number and duration of fights were determined at the group level using continuous sampling. A fight was considered when two or more animals performed a sequence of the following behaviours for $>3$ s.: biting, head knocking, pushing and shoving each other, with no greater intervals than $10 \mathrm{~s}$. between behaviour occurrences (D'Eath, 2002; Pitts, Weary, Pajor, \& Fraser, 2000). Proportion of pigs lying down, and number and duration of fights were calculated per period of $30 \mathrm{~min}$. in two ways: forward from the beginning of lairage and backward prior to slaughter. To assess the recovery rate of the pigs after transport, the time necessary for $75 \%$ of the pigs from the same pen to rest (latency to rest) was also determined by the percentage of pigs lying down. Video recordings were analyzed by two trained observers and inter-observer agreement was $94.2 \%$.

\subsection{Blood parameters}

Blood samples were collected from the bleeding wound of 210 pigs (15 pigs/treatments/replicates) in a plastic cup and lactate values were immediately assessed in duplicate with the Lactate Scout Analyzer (Lactate Scout, EKF Diagnostic GmbH, Magdeburg, Germany) by dipping two test strips (two strips/animal) in the collected sample. Later on, $10 \mathrm{~mL}$ of blood were collected in a tube (BD Vacutainers; VWR International Ltd., Montreal, Canada) to extract the serum for creatine kinase (CK) analysis. Serum samples were kept at room temperature $\left(\sim 23^{\circ} \mathrm{C}\right)$ for $1 \mathrm{~h}$ before refrigeration at $4{ }^{\circ} \mathrm{C}$. The next day, serum samples were centrifuged at $4{ }^{\circ} \mathrm{C}$ for $12 \mathrm{~min}$ at $1400 \mathrm{~g}$, transferred to Eppendorf tubes $(1.5 \mathrm{~mL})$, and stored at $-80{ }^{\circ} \mathrm{C}$ until analysis. $\mathrm{CK}$ concentrations were measured with a creatine kinase-sl kit (Creatine Kinase-SL Assay of Chemicals Diagnostic Limited, Vancouver, Canada). The intra-assay coefficient of variation for CK was $5.49 \%$.

\subsection{Carcass and meat quality measures}

After slaughter, carcasses were eviscerated, split and chilled according to standard commercial practices. Hot carcass weight (HCW) was recorded and used to calculate carcass yield. Lean yield was obtained by measuring carcass fat and lean depth at the 3rd/4th last rib level by a Destron optical probe.

Meat quality was assessed in the carcass of the same pigs that were blood sampled ( 210 or 15 carcasses/treatments/replicates) by measuring $\mathrm{pH}$ at $1 \mathrm{~h}\left(\mathrm{pH}_{1}\right)$ and $24 \mathrm{~h}(\mathrm{pHu})$ post-mortem with a $\mathrm{pH}$ meter

Table 1

Description of pig behaviours and interventions of the handler during loading (adapted from Weschenfelder et al., 2012). Description

$\begin{array}{ll}\text { Pig behaviour } & \text { Leg of pig splits away from the other legs or pig falls down (at least } 2 \text { legs buckled under) } \\ \text { Slip/fall } & \text { Pig mounts another pig, with its } 2 \text { front legs on the back of the other pig } \\ \text { Overlap } & \text { Pig makes a } 180^{\circ} \text { turn, ending with its rear extended in the direction of intended movement } \\ 180^{\circ} \text { turn } & \text { Pig moves at least } 2 \text { steps rearward, opposite the direction of intended motion } \\ \text { Back-up } & \text { Pig moves in the intended direction with its body oriented in the opposite direction } \\ \text { Backward } & \text { Head of pig goes under the body of another pig } \\ \text { Underlap } & \text { Pig vocalizes } \\ \text { Vocalize } & \text { Pig stops for }>2 \mathrm{~s} \text {. } \\ \text { Balk } & \text { Pig is squeezed at the door, corridor, or the exit of the ramp (or at the trailer door, when unloading) } \\ \text { Squeeze } & \end{array}$


(Oakton Instruments Model pH 100 Series, Nilis, IL) fitted with a spear type electrode (Cole Palmer Instrument Company, Vernon Hills, IL) and an automatic temperature compensation probe by insertion in the Longissimus thoracis (LT) between the 3rd/4th last rib (Canadian grading site), Semimenbranosus (SM) and in the Adductor (AD) muscles. At $24 \mathrm{~h}$ post-mortem the following measurements were conducted in the LT muscle in the carcass grading site region: subjective colour score using the Japanese Colour Standards (JCS) ranging from $1=$ pale to 6 = dark colour (Nakai, Saito, Ikeda, Ando, \& Komatsu, 1975), instrumental colour ( $\mathrm{L}^{*}, \mathrm{a}^{*}$ and $\mathrm{b}^{*}$ values) using a Minolta Chromameter (CR-300; Minolta Canada Inc., Mississauga, Canada) equipped with a $25-\mathrm{mm}$ aperture, $0^{\circ}$ viewing angle, and D65 illuminant, and drip loss using the modified EZ-driploss method as describe by Correa, Méthot, and Faucitano (2007). Briefly, $25 \mathrm{~mm}$ diameter cores were removed from the center of $2.5 \mathrm{~cm}$ thick LT muscle cross-section, weighed and placed into plastic drip loss containers (Christensen Aps Industrivaengetand, Hilleroed, Denmark), before being stored for $48 \mathrm{~h}$ at $4{ }^{\circ} \mathrm{C}$. At the end of the $48 \mathrm{~h}$ storage period, muscle cores were removed from their container, surface moisture was carefully dabbed, cores were reweighed, and drip loss percentage was calculated by dividing the difference between initial and final core weights by the initial core weight.

\subsection{Statistical analysis}

Statistical analyses were carried out according to a generalized randomized complete block design to check any effects of treatments by analysis of variance in one-way ANOVA. The MIXED procedure of SAS (2002) (SAS Inst. Inc., Cary, NC) was applied to analyze the physiological data using the group as the experimental unit and meat quality data using the individual animal as the experimental unit. Values of blood lactate and CK concentration were log-transformed $(\log 10)$ for data normalization before analysis. Loading behaviour data were analyzed with the FREQ procedure using the loading group as the experimental unit. As behaviours, such as back-up, $180^{\circ}$ turn, go backward, slip/fall, underlapping, vocalizing, squeeze and noise, had low frequencies, they were transformed to binary variables and were analyzed with the LOGISTIC procedure of SAS. Lairage behaviour data were analyzed as repeated measures over time (periods of $30 \mathrm{~min}$.) after transformation (angular, square root and logarithmic transformations for percentage of pigs lying down, number of fights and total duration of fights, respectively). The model included treatment, time period and their interaction as fixed effects, while week was used as a repetition. Results from lairage behaviour are presented as back-transformed least square means and confidence interval. Meat quality classes were compared

Table 2

Effects of feed withdrawal as mostly applied on-farm (FARM) or at slaughter plant (PLANT) on the frequency of pig behaviours and interventions of handlers at loading.

\begin{tabular}{|c|c|c|c|c|}
\hline \multicolumn{5}{|c|}{ Feed withdrawal treatment } \\
\hline Item & FARM & PLANT & SEM & $P$ \\
\hline \multicolumn{5}{|l|}{ Pig behaviour } \\
\hline Slip/fall ${ }^{\mathrm{a}}$ & 21.7 & 16.7 & & 0.81 \\
\hline Overlap ${ }^{a}$ & 3.3 & 3.3 & & 1.00 \\
\hline $180^{\circ}$ turn $^{\mathrm{a}}$ & 30.0 & 13.3 & & 0.03 \\
\hline Back-up ${ }^{a}$ & 41.7 & 40.0 & & 0.85 \\
\hline Backward $^{\mathrm{a}}$ & 20.0 & 6.7 & & 0.03 \\
\hline Underlap $^{\mathrm{a}}$ & 10.0 & 11.7 & & 0.77 \\
\hline Vocalize $^{\mathrm{a}}$ & 10.0 & 1.7 & & 0.05 \\
\hline Squeeze ${ }^{a}$ & 21.7 & 10.0 & & 0.08 \\
\hline Balk $^{\mathrm{b}}$ & 8.5 & 8.8 & 0.55 & 0.75 \\
\hline \multicolumn{5}{|c|}{ Intervention of handler } \\
\hline Rattle noise ${ }^{\mathrm{a}}$ & 6.7 & 8.3 & & 0.73 \\
\hline Vocal sound ${ }^{\mathrm{b}}$ & 14.32 & 15.18 & 1.04 & 0.56 \\
\hline Physical contact $^{\mathrm{b}}$ & 50.62 & 48.93 & 2.20 & 0.59 \\
\hline
\end{tabular}

\footnotetext{
a Percentage of groups where the behaviour was observed.
}

b Average frequency per group of 5 pigs. by treatment using the Fischer Exact Test. A probability level of $P<0.05$ was chosen as the limit for statistical significance in all tests. Whereas, probability levels of $P \leq 0.10$ were considered as a tendency.

\section{Results and discussion}

\subsection{Behavioural response}

\subsubsection{Behaviour at loading}

The fasting condition of pigs at the time of loading affected their behaviour while being moved through the farm alley to the truck gate (Table 2). Compared with FARM pigs, PLANT pigs showed less behaviours of going backward and $180^{\circ}$ turn $(P=0.03$ for both), and vocalized less $(P=0.05)$ during loading. However, these behaviours did not result in different frequency of interventions of handler between the two groups $(P>0.10)$. The use of a trained handler and the small group size in this study may have compensated for these fear behaviours and facilitated handling. Overall, these observations do not confirm the impression that fasted groups of pigs are easier to handle (Eikelenboom et al., 1991). The behaviour showed by FARM pigs at loading may be explained by the increased frustration and excitement caused by hunger and feed restriction (Arnone \& Dantzer, 1980; Lewis, 1999; Munksgaard \& Simonsen, 1996).

\subsubsection{Behaviour in lairage}

Pigs fasted at the farm tended to have a shorter latency to lie down than pigs fasted at the abattoir ( 35.7 vs. $46.7 \pm 5.6$ min.; $P=0.06$ ). During the first $2 \mathrm{~h}$ of lairage, a greater $(P<0.01)$ proportion of FARM pigs were lying (Fig. 1a), while PLANT pigs showed a higher $(P<0.05)$ number of fights and a longer $(P<0.01)$ total duration of fights for several periods (Fig. 1b, c). Moreover, fighting behaviour of PLANT pigs continued with the same intensity during the third hour of lairage (Fig. 1b, c). However, during the last $2 \mathrm{~h}$ of lairage, FARM pigs laid down less and fought more than PLANT pigs ( $P<0.05$; Fig. 2a, b, c). The shorter latency to rest in FARM pigs on arrival at the pen may indicate their need to recover from physical exhaustion caused by the additive effect of feed restriction, handling and transportation (Brandt \& Aaslying, 2015). In this metabolic condition, in fact, pigs prefer settling down to rest rather than doing other activities (i.e. exploring the pen or fighting with the new pen-mates). These results are in contrast with Brown, Knowles, Edwards, and Warriss (1999) who reported a greater activity (fighting and drinking) on arrival at the lairage pen in pigs fasted for longer time ( $18 \mathrm{vs.}<1 \mathrm{~h}$ ). Fernandez, Meunier-Saluan, Ecolan, and Mormède (1995) also found a greater activity in fasted pigs ( $24 \mathrm{vs.} 0 \mathrm{~h}$ ) than fed ones that spent more time lying down. In contrast, in the present study, PLANT pigs started fighting intensively with unfamiliar pen-mates from the beginning of lairage and kept fighting constantly up to $3 \mathrm{~h}$ of lairage (limit of the observation time). Several studies already reported a more extended fighting rate in pigs kept in lairage for longer periods (overnight to $>24 \mathrm{~h}$ vs. $3 \mathrm{~h}$ ) as a result of mixing (Guàrdia et al., 2009; Murray \& Jones, 1994; Warriss, Brown, Edwards, \& Knowles, 1998). Because of the longer time spent in lairage resulting in more extended fighting PLANT pigs got fatigued over time and were mostly resting and recovering at the end of lairage time. Brown et al. (1999) also reported a significant reduction in fights between pigs after $1 \mathrm{~h}$ of lairage. Possibly, FARM pigs, which fought less during the first $2 \mathrm{~h}$ of lairage, recovered from the fatigue of transport and handling during this period in contrast to PLANT pigs, but this translated into greater fighting just before slaughter in FARM pigs.

\subsection{Physiological response}

The variation of both lactate and CK levels in blood indicates the pig response to short and long-term physical stress, respectively, resulting from muscle fatigue or damage (Broom, 1995; Edwards et al., 2010a, 2010b). In this study, despite the greater activity observed for PLANT 

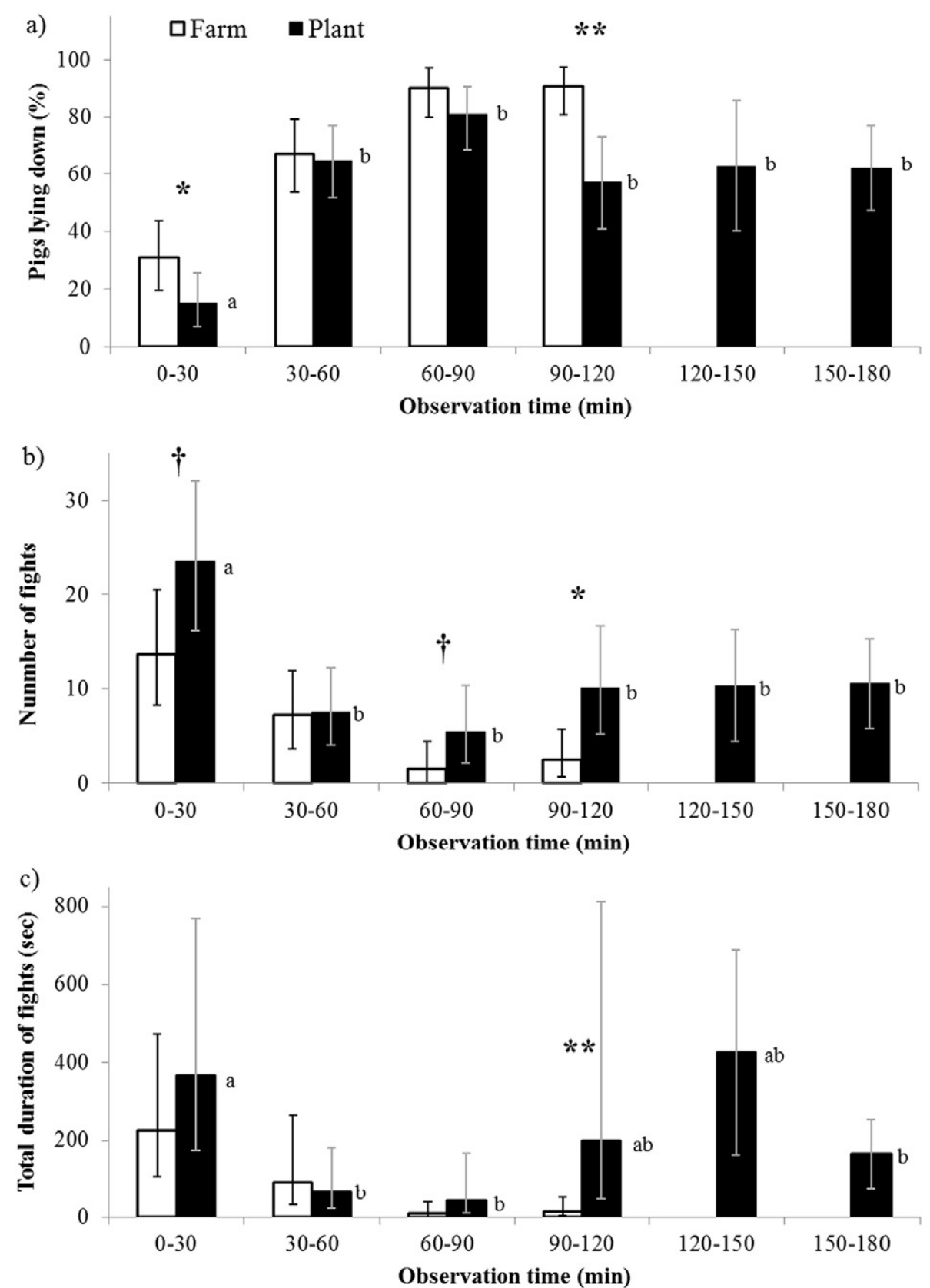

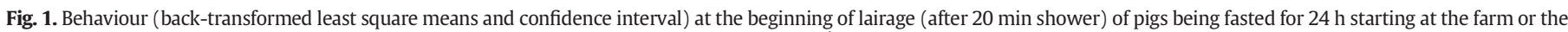

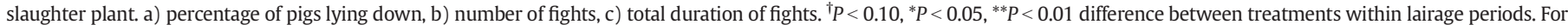
PLANT pigs only, black bars lacking a common superscript letter differ $(P<0.05)$.

pigs in lairage, no difference in lactate and $\mathrm{CK}$ concentration was found in exsanguination blood between the two fasting groups $(P=0.76$ and $P=0.96$, respectively; Table 3 ). The lack of effect of treatments on whole blood lactate may indicate that thanks to the adequate lairage conditions (sufficient space allowance to lie down) PLANT pigs had sufficient time to rest and recover from the vigorous initial fighting activity. It is known that if pigs are allowed to rest after physical exercise blood lactate returns to basal levels within $2 \mathrm{~h}$ (Edwards et al., 2010b). The greater fighting activity of FARM pigs during the last hours of lairage may have increased their blood lactate concentrations eventually levelling those of PLANT pigs. Overall, in both groups, the blood lactate levels at exsanguination were $>4 \mathrm{mM}$, which is the resting level of blood lactate reported for market-weight pigs (Edwards et al., 2011), indicating a general status of fatigue in all pigs in this study. Similarly, the lagged expression of fighting behaviour between the two groups during lairage may explain the lack of difference in blood CK level at slaughter, which achieves the maximum concentration peak at $6 \mathrm{~h}$ after the stress and does not return to basal levels until 48 h (Anderson, 2010 cited by Correa et al., 2013). Thus, it may appear that at the time of slaughter blood CK levels were increasing in FARM pigs and descending in PLANT pigs, which once again explains the lack of difference in the physiological response between the two fasting groups likely resulting from the confounding effect of the different time spent in lairage on these pigs' recovery rate.

\subsection{Carcass quality traits}

When compared to FARM pigs, PLANT pigs neither differed in HCW ( 85.7 vs. $85.3 \mathrm{~kg}$, SEM: $0.3 ; P=0.28$ ) nor in carcass yield ( $69.3 \%$ for both groups, SEM: $0.2 ; P=0.99$ ) in this study. This result is not surprising as 
a)

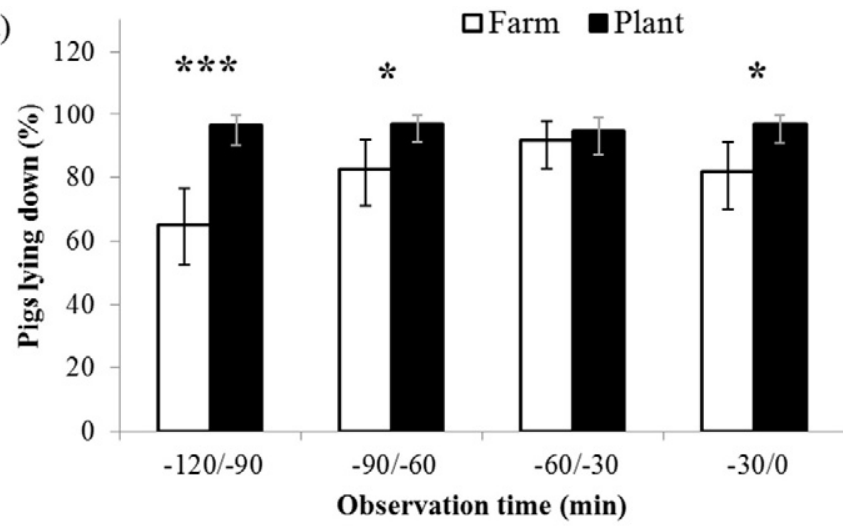

b)
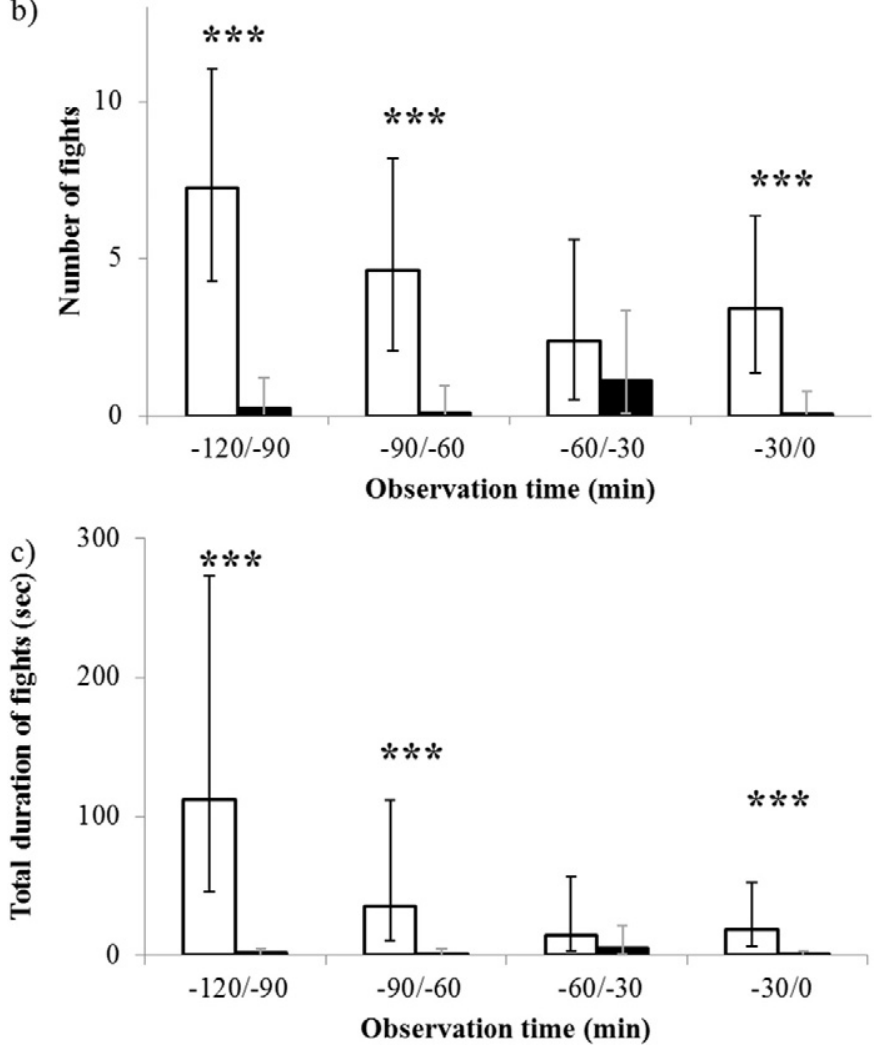

Fig. 2. Behaviour (back transformed least square means and confidence interval) at the end of lairage (from 120 min to the beginning of the last shower) of pigs being fasted for $24 \mathrm{~h}$ starting at the farm or the slaughter plant. a) percentage of pigs lying down, b) number of fights, c) total duration of fights. ${ }^{*} P<0.05,{ }^{* * *} P<0.001$ difference between treatments within lairage periods.

only fasting time in excess of $24 \mathrm{~h}$ preslaughter showed to result in liveweight losses, in terms of $100 \mathrm{~g}$ weight loss per hour, and consequently in carcass yield losses in pigs in previous studies (Faucitano et al., 2010). Finally, these results show that, no matter where a $24 \mathrm{~h}$ fasting time is applied through the preslaughter period, this duration has no impact on carcass weight and yield losses.

Table 3

Effects of feed withdrawal as mostly applied on-farm (FARM) or at slaughter plant (PLANT) on exsanguination blood parameters ${ }^{\mathrm{a}}$.

\begin{tabular}{lccc}
\hline & \multicolumn{2}{l}{ Feed withdrawal treatment } & \\
\cline { 2 - 3 } Parameters & FARM $(n=105)$ & PLANT $(n=105)$ & $P$ \\
\hline Lactate $(\mathrm{mMol})$ & $9.98[8.88-11.28]$ & $9.76[8.64-11.03]$ & 0.76 \\
CK $($ IU $/ \mathrm{L})$ & $3173[2711-3712]$ & $3,187[2,723-3,729]$ & 0.96
\end{tabular}

a The values between brackets are lower and upper value of confidence interval.

\subsection{Meat quality traits}

In this study, the applied fasting time strategies only influenced the JCS score and drip loss percent of the LT muscle, with PLANT loins being darker (higher JCS scores; $P=0.02$ ) and drier (lower drip loss percent; $P=0.03$ ) than those from FARM pigs (Table 4). Indeed, when PLANT loins were classified in darker and drier or drier-only quality classes based on the JCS score $(>3.5)$ and drip loss percent value $(<2 \%)$, a greater number of darker and drier or drier loins were found in PLANT carcasses than in FARM carcasses (17 vs. 12 and 81 vs. 72, respectively). However, this difference was only numerical $(P=0.43$ and $P=0.20$, respectively). The variation in pork colour and drip loss, but not in the pHu values, may be indicative of a mild fatigue metabolic condition of PLANT pigs at slaughter that did not result in a sufficient depletion of muscle glycogen content to increase $\mathrm{pHu}$, even in locomotor muscles, such as SM and AD muscles, that are more prone to glycogen exhaustion after feed restriction and physical exercise (Rocha, Dionne, Saucier, Nannoni, \& Faucitano, 2015; Fernandez, Meunier-Saluan, Ecolan, \& Mormède, 1995). According to Henckel, Karlsson, Jensen, Oksbjerg, and Petersen (2002), pHu values only increase when muscle glycogen content at slaughter is lower than $53 \mu \mathrm{mol} / \mathrm{g}$. The only mild fatigue status of these pigs at slaughter is also confirmed by the above-mentioned lack of variation in blood CK and lactate levels at exsanguination, which again may show the difference in recovery rate between pigs likely due to the different lairage time applied. Differently from the visual colour score, the Minolta $\mathrm{L}^{*}$ value, indicator of colour lightness, was not influenced by the fasting strategy (including lairage time) applied in this study. This result may be explained by the confounding effect of the light reflectance of marbling fat, which was not evaluated in this study. High marbling fat scores have been, in fact, associated with higher $\mathrm{L}^{*}$ values due to fat colour reflectance, while they have no influence on visual colour scores (Jones, Tong, Campbell, \& Dyck, 1994; Van der Wal, Olsman, Garssen, \& Engel, 1992).

\section{Conclusions}

Within the pork chain, it is generally agreed that a feed withdrawal time of $24 \mathrm{~h}$ preslaughter is the best compromise to obtain optimal carcass yield and pork safety. However, under split-marketing conditions the management of this practice, in terms of the timing of its application (at the farm or at the abattoir), is at the discretion of the producer or abattoir manager. Based on the results of this study, the choice of applying most of the fasting time at the abattoir rather than at the farm may not be appropriate as it prevents pigs from resting before slaughter and increases the risk for DFD-like pork production due to increased activity

Table 4

Effects of feed withdrawal as applied on-farm or at the slaughter plant on meat quality traits as assessed in the Longissimus thoracis (LT), Semimembranosus (SM) and Adductor (AD) muscles.

\begin{tabular}{lllll}
\hline & \multicolumn{2}{l}{ Feed withdrawal treatment } & \\
\cline { 2 - 3 } Variable & FARM $(n=105)$ & PLANT $(n=105)$ & SEM & $P$ \\
\hline LT muscle & & & & \\
$\mathrm{pH}_{1}$ & 6.42 & 6.47 & 0.05 & 0.34 \\
$\mathrm{pHu}$ & 5.77 & 5.76 & 0.04 & 0.76 \\
$L^{*}$ & 52.67 & 52.08 & 0.58 & 0.19 \\
$a^{*}$ & 9.50 & 9.75 & 0.23 & 0.21 \\
$b^{*}$ & 5.99 & 5.91 & 0.16 & 0.61 \\
$\mathrm{JCS}^{1}$ & 2.6 & 2.8 & 0.09 & 0.02 \\
Drip loss, $\%$ & 1.8 & 1.3 & 0.14 & 0.03 \\
SM muscle & & & & \\
$\mathrm{pH}$ & & 6.43 & 0.08 & 0.48 \\
$\mathrm{pHu}$ & 6.39 & 5.80 & 0.05 & 0.10 \\
AD muscle & 5.84 & & & \\
$\mathrm{pHu}$ & & 5.95 & 0.05 & 0.29 \\
\hline
\end{tabular}

1 JCS: Japanese colour scales ( $1=$ pale to $6=$ dark; Nakai et al., 1975). 
(fighting) in mixed groups of pigs that have to be kept in lairage for long time.

\section{Acknowledgements}

We appreciate the assistance of S. Horth, M.J. St.-Louis, C. Cavalheiro, S. Conte, A. de Castro, D. Morissette, M. Gil and R. Sommavilla for the behaviour data collection and analysis and meat quality measurements at the abattoir. Special thanks go to S. Méthot for his support with the statistical analysis. The authors are grateful to Lucyporc Inc. for the financial support and the National Research Council of Brazil (CNPq) for the scholarship granted to F. Dalla Costa to conduct his graduate studies.

\section{References}

Aalhus, J. L., Murray, A. C., Jones, S. D. M., Tong, A. K. W., Raymond, D. P., \& Weir, L. (1992) Environmental conditions for swine during the marketing for slaughter: A national review. Technical bulletin 1992-6E. Ottawa, ON: Agriculture Canada, Research Branch.

Arnone, M., \& Dantzer, R. (1980). Does frustration induce aggression in pigs? Applied Animal Ethology, 6, 351-362.

Averós, X., Knowles, T. G., Brown, S. N., Warriss, P. D., \& Gonsálvez, L. F. (2008). Factors affecting the mortality of pigs being transported to slaughter. Veterinary Record, 163, 386-390.

Bradshaw, R. H., Parrott, R. F., Goode, J. A., Lloyd, D. M., Rodway, R. G., \& Broom, D. M. (1996). Behavioural and hormonal responses of pigs during transport: Effect of mixing and duration of journey. Animal Science, 62, 547-554.

Brandt, P., \& Aaslying, M. D. (2015). Welfare measurements of finishing pigs on the day of slaughter: A review. Meat Science, 103, 13-23.

Broom, D. M. (1995). Quantifying pig welfare during transport using physiological measures. In A. Schütte (Ed.), Landbauforschung Völkenrode, Proceedings EU seminar "new information on welfare and meat quality of pigs as related to handling, transport and lairage conditions" (pp. 3-10) (Mariensee, Germany).

Brown, S. N., Knowles, T. G., Edwards, J. E., \& Warriss, P. D. (1999). Relationship between food deprivation before transport and aggression in pigs held in lairage before slaughter. Veterinary Record, 145, 630-634.

Canadian Council on Animal Care (2009). Guide to the Care and Use of Experimental Animals. Ottawa, Canada: Canadian Council on Animal Care.

Correa, J. A., Gonyou, H. W., Torrey, S., Widowski, T. M., Crowe, T. G., LaForest, J. -P., \& Faucitano, L. (2013). Welfare and carcass and meat quality of pigs being transported for 2 hours using two vehicle types during two seasons of the year. Canadian Journal of Animal Science, 93, 43-55.

Correa, J. A., Méthot, S., \& Faucitano, L. (2007). A modified meat juice container (EZ-DripLoss) procedure for a more reliable assessment of drip loss and related quality changes in pork meat. Journal of Muscle Foods, 18, 67-77.

D'Eath, R. B. (2002). Individual aggressiveness measured in a resident-intruder test predicts the persistence of aggressive behaviour and weight gain of young pigs after mixing. Applied Animal Behaviour Science, 77, 267-283.

Edwards, L. N., Engle, T. E., Grandin, T., Ritter, M. J., Sosnicki, A., Carlson, B. A., \& Anderson, D. B. (2011). The effects of distance traveled during loading, lairage time prior to slaughter, and distance traveled to the stunning area on blood lactate concentration of pigs in a commercial packing plant. Professional Animal Scientists, 27, 485-491.

Edwards, L. N., Grandin, T., Engle, T. E., Porter, S. P., Ritter, M. J., Sosnicki, A. A., \& Anderson, D. B. (2010a). Use of exsanguination blood lactate to assess the quality of preslaughter pig handling. Meat Science, 86, 384-390.

Edwards, L. N., Grandin, T., Engle, T. E., Porter, S. P., Ritter, M. J., Sosnicki, A. A., ... Anderson, D. B. (2010b). Relationship of blood lactate and meat quality in market hogs. Presentation at the reciprocal meat conference, Lubbock, TX (https://www.researchgate.net/ publication/260983276_Relationship_of_blood_lactate_and_meat_quality_in_market_ hogs, accessed on January 25, 2016).

Eikelenboom, G., Hoving-Bolink, A. H., \& Sybesma, W. (1991). Effect of feed withdrawal before delivery on pork quality and carcass yield. Meat Science, 29, 25-30.

Faucitano, L., Chevillon, P., \& Ellis, M. (2010). Effects of feed withdrawal prior to slaughter and nutrition on stomach weight, and carcass and meat quality in pigs. Livestock Science, $127,110-114$.
Fernandez, X., Meunier-Saluan, M. -C., Ecolan, P., \& Mormède, P. (1995). Interactive effect of food deprivation and agonistic behaviour on blood parameters and muscle glycogen in pigs. Physiology and Behavior, 58, 337-345.

Guàrdia, M. D., Estany, J., Balasch, S., Oliver, M. A., Gispert, M., \& Diestre, A. (2009). Risk assessment of skin damage due to pre-slaughter conditions and RYR1 gene in pigs. Meat Science, 81, 745-751.

Guàrdia, M. D., Estany, J., Balash, S., Oliver, M. A., Gispert, M., \& Diestre, A. (2005). Risk assessment of DFD condition due to pre-slaughter conditions and RYR1 gene in pigs. Meat Science, 70, 709-716.

Guàrdia, M. D., Gispert, M., \& Diestre, A. (1996). Mortality rates during transport and lairage in pigs for slaughter. Meat Focus International, 10, 362-366.

Henckel, P., Karlsson, A., Jensen, M. T., Oksbjerg, N., \& Petersen, J. S. (2002). Metabolic conditions in porcine longissimus muscle immediately pre-slaughter and its influence on peri- and post mortem energy metabolism. Meat Science, 62, 145-155.

Jones, S. D. M., Tong, A. K. W., Campbell, C., \& Dyck, R. (1994). The effects of fat thickness and degree of marbling on pork colour and structure. Canadian Journal of Animal Science, 74, 155-157.

Lewis, N. J. (1999). Frustration of goal-directed behaviour in swine. Applied Animal Behaviour Science, 64, 19-29.

Munksgaard, L., \& Simonsen, H. B. (1996). Behavioural and pituitary adrenal-axis responses of dairy cows to social isolation and deprivation of lying down. Journal of Animal Science, 74, 769-778.

Murray, A. C., \& Jones, S. D. M. (1994). The effect of mixing, feed restriction and genotype with respect to stress susceptibility on pork carcass and meat quality. Canadian Journal of Animal Science, 74, 587-594.

Nakai, H., Saito, F., Ikeda, T., Ando, S., \& Komatsu, A. (1975). Standards models of pork color. Bulletin of National Institute of Animal Industry, 30, 69-74.

National Farm Animal Care Council (2014). Codes of practice for the care and handling of pigs. https://www.nfacc.ca/codes-of-practice/pigs (accessed on January 25, 2016)

Peeters, E., Deprez, K., Beckers, F., De Baerdemaeker, J., Aubert, A. E., \& Geers, R. (2008). Effect of driver and driving style on the stress responses of pigs during a short journey by trailer. Animal Welfare, 17, 189-196.

Pitts, A. D., Weary, D. M., Pajor, E. A., \& Fraser, D. (2000). Mixing at young ages reduces fighting in unacquainted domestic pigs. Applied Animal Behaviour Science, 68, 191-197.

Rocha, L. M., Dionne, A., Saucier, L., Nannoni, E., \& Faucitano, L. (2015). Hand-held lactate analyzer as a tool for the real-time measurement of physical fatigue before slaughter and pork quality prediction. Animal, 9, 707-714.

SAS (2002). Statistical analysis system. Release 9.1. Cary, NC, USA: SAS Institute Inc.

Saucier, L., Bernier, D., Bergeron, R., Giguere, A., Methot, S., \& Faucitano, L. (2007). Effect of feed texture, meal frequency and pre-slaughter fasting on behaviour, stomach content and carcass microbial quality in pigs. Canadian Journal of Animal Science, 87 479-487.

Schwartzkopf-Genswein, K. S., Faucitano, L., Dadgar, S., Shand, P., González, L. A., \& Crowe, T. G. (2012). Road transport of cattle, swine and poultry in North America and its impact on animal welfare, carcass and meat quality: A review. Meat Science, 92, 227-243.

Stewart, G., Ritter, M., Culbertson, G., Mann, G., \& Wofford, R. (2008). Effects of previous handling and feed withdrawal prior to loading on transport losses in market weight pigs. Proceedings of American Association of Swine Veterinarians. San Diego, CA (pp. 359-362).

Van der Wal, P. G., Olsman, W. J., Garssen, G. J., \& Engel, B. (1992). Marbling, intramuscular fat and meat colour of Dutch pork. Meat Science, 32, 351-355.

Viau, J., \& Champagne, D. (1998). La mise à jeun chez le porc avant l'abattage. Report of centre de développement du porc du Québec, Quebec City, Canada.

Warriss, P. D., Brown, S. N., Edwards, J. E., \& Knowles, T. G. (1998). Effect of lairage time on levels of stress and meat quality in pigs. Animal Science, 66, 255-261.

Weeding, C. M., Guise, H. J., \& Penny, R. H. C. (1993). Factors influencing the welfare and carcass and meat quality of pigs: The use of water sprays in lairage. Animal Production, 56, 393-397.

Weschenfelder, A. V., Torrey, S., Devillers, N., Crowe, T., Bassols, A., Saco, Y., ... Faucitano, L (2012). Effects of trailer design on animal welfare parameters and carcass and meat quality of three Pietrain crosses being transported over a long distance. Journal of Animal Science, 90, 3220-3231. 